\title{
Construction safety and digital design: a review
}

Article

Accepted Version

Zhou, W., Whyte, J. and Sacks, R. (2012) Construction safety and digital design: a review. Automation in Construction, 22. pp. 102-111. ISSN 0926-5805 doi:

https://doi.org/10.1016/j.autcon.2011.07.005 Available at https://centaur.reading.ac.uk/22357/

It is advisable to refer to the publisher's version if you intend to cite from the work. See Guidance on citing.

Published version at: http://www.sciencedirect.com/science/journal/09265805

To link to this article DOI: http://dx.doi.org/10.1016/j.autcon.2011.07.005

Publisher: Elsevier

All outputs in CentAUR are protected by Intellectual Property Rights law, including copyright law. Copyright and IPR is retained by the creators or other copyright holders. Terms and conditions for use of this material are defined in the End User Agreement.

\section{www.reading.ac.uk/centaur}

\section{CentAUR}

Central Archive at the University of Reading

Reading's research outputs online 


\title{
Construction Safety and Digital Design: A Review
}

Published version:

Zhou, W., Whyte, J. and Sacks, R. (2012) Construction Safety and Digital Design: A Review, Automation in Construction, 22, 102-111.

http://dx.doi.org/10.1016/j.autcon.2011.07.005

The final, definitive version of this paper has been published in Automation in Construction, 22, 2012 by

Elsevier Ltd, All rights reserved. (C) This is a revised personal version, posted by the second author on the University of Reading website under the terms of the contributor agreement. Please cite the published version and refer to it for pages, etc.

\begin{abstract}
As digital technologies become widely used in designing buildings and infrastructure, questions arise about their impacts on construction safety. This review explores relationships between construction safety and digital design practices with the aim of fostering and directing further research. It surveys state-of-the-art research on databases, virtual reality, geographic information systems, 4D CAD, building information modeling and sensing technologies, finding various digital tools for addressing safety issues in the construction phase, but few tools to support design for construction safety. It also considers a literature on safety critical, digital and design practices that raises a general concern about 'mindlessness' in the use of technologies, and has implications for the emerging research agenda around construction safety and digital design. Bringing these strands of literature together suggests new kinds of interventions, such as the development of tools and processes for using digital models to promote mindfulness through multi-party collaboration on safety.
\end{abstract}

Keywords: digital models, construction safety, safety practice, design. 


\section{Introduction}

Do computers lull the designers of buildings and infrastructure into seeing themselves as precision 'watchmakers', ignoring the uncertainty inherent in fabrication and construction processes on large-scale projects? Or can digital technologies instead inform designers about the dangerous situations that might arise from their design decisions? With building modeling, for example, greater detail is developed earlier in a project. Can this enhance designers' awareness of construction safety issues, or can it inadvertently lead to these issues being overlooked? At the heart of this review paper are debates about the potential to mobilize digital technologies in design to sustain and develop safe construction practices.

Safety is a major issue across global construction industries. There were 9.5 fatalities reported per 100,000 construction workers in Europe in 2006 [1] and 11 per 100,000 in the US in 2007 [2]. Accident rates in construction remain twice those for manufacturing, with 53 construction workers in the UK dying in 2008/9 and thousands more sustaining major injuries at work [45]. While safety has been improving in many countries [5], loss of life through construction accidents is unacceptable [18]. The main causes of such accidents are well documented. They include falls from height; being struck by a moving vehicle; being struck by a moving/falling object; or becoming trapped by something overturning/collapsing [31]. Such errors in complex and hazardous environments have often been regarded in the literature, as either the failure of individuals, where individual carelessness led to accidents such as falls from height or the failure of complex organizations [49], where a wider set of organizational structures and practices led to individuals being put into unsafe situations; although recent work describes accidents resulting as multiple factors interact [51].

While the physical task of putting together buildings and infrastructure remains a locally embedded physical activity, it is also changed by the digital economy, which brings with it new 'splintered yet connected' ways of working across global networks of design services and product supply $[12,40]$. One relevant strand of research has focused on the use of digital technologies such as online databases, Virtual Reality (VR), Geographic Information Systems (GIS), 4D Computer Aided Design (4D CAD) and Building Information Modeling (BIM), sensing/warning technologies etc to develop new tools for hazard prevention and safe project delivery. Yet another strand of literature, involving empirical studies of practice that draw on theories of organizations, raises a more general concern that digital technologies may have unintended as well as intended impacts. A review of these two literatures is motivated by questions, such as those at the start of the paper, which have been raised in conversations with senior engineers on large construction sites. 
With the aim of fostering and directing further research on the application of digital technologies in design for construction safety, this review article brings together these two strands. After outlining the legislation and practice of design for safety, it first surveys the state-of-the-art in the application of digital technologies - online databases, VR, GIS, 4D CAD, BIM, and sensing/warning technologies - to construction safety in general and to safety through design in particular, articulating the applications that have been developed for use at project, product, process and operation levels. The scope of this survey covers articles in leading journals (including, but not limited to: Automation in Construction; Construction Management and Economics; Engineering,

Construction and Architectural Management; Information Technology in Construction; International Journal of Project Management; Journal of Architectural Engineering; Journal of Computing in Civil Engineering; Journal of Construction Engineering and Management; Journal of Safety Research; and Safety Science) from 1990 onward, numerous books, government regulations and other sources. The second strand of the review focuses on a literature that discusses safety critical, digital and design practices, drawing on wider theories of organization. This work is beginning to be discussed and developed through articles in the above journals [e.g. 43] as well as in the wider built environment and literatures. Yet, as there is no work within this strand that deals explicitly with relationships between construction safety and digital design, it is outlined more briefly, with a focus on bringing out implications for research in the first strand; as well as identifying areas of further work to explore these relationships.

The section below sets the scene by giving an overview of the existing research and initiatives concerning safety by design. Then the first strand of literature is discussed in the next two sections: where Section 3 discusses digital applications and tools in construction safety management in general, and Section 4 focuses on digital applications and tools that have been developed for safety by design in particular. The review of this strand finds that while various digital tools have been developed for use in the construction phase, few are available to support design for construction safety. The second strand of literature is then discussed in Section 5, which describes this work on safe practices and the intended and unintended impacts of digital technologies. The review of this strand finds a need for further research to investigate relationships between construction safety and digital design. The Discussions and conclusions section brings these strands together, suggesting new kinds of interventions, such as the development of tools and processes for multi-party discussion of safety around digital models. 


\section{Construction safety through design}

Construction safety should, according to Szymberski [58], be a prime consideration in the conceptual and preliminary design phases. His hypothetical time/safety influence curve illustrates the idea that the ability to influence construction site safety is progressively lost as the project moves into the construction phase, with a significant opportunity in design. Until recent legislation in the UK, France and Australia, however, designers' consideration of construction safety has been largely voluntary [21]. In the USA, construction contracts and regulatory requirements from the Occupational Safety and Health Administration (OSHA) clearly place the burdens for worker safety solely on the constructor [8]. This approach is still widespread across many countries, but has been changing since more parties have been brought into litigation regarding worker injuries. A recent study of the effect of European directives on construction workplace accidents, shows a statistical decrease in incidents since legislation came into force [3]. Project owners have also become more concerned about safety performance on their projects [21]. Recent research indicates that: 'many designers still think that safety is 'nothing to do with me' although there are a small cohort who want to engage and are having difficulty doing this because they do not fully understand what good practice looks like.' [11: p. 12].

The Construction (Design and Management) (CDM) regulations bring Health and Safety $(\mathrm{H} \& \mathrm{~S})^{1}$ management, on an obligatory basis, into the planning and design of construction work in the UK. Thus the contractor is no longer left with the sole responsibility for safety during construction. The aim of the CDM Regulations is to bring about a culture change in the construction industry by requiring all those involved in the development and construction process to consider both health and safety issues. Baxendale et al. [7] argue that the philosophy behind this is to establish a team that will have the competence and resources to manage the project without undue risk to health and safety. The appointment of a planning supervisor, namely the CDM coordinator following the new CDM regulation 2007 release, is central to a client's responsibilities. The CDM coordinator should be appointed as early as possible to allow adequate time to address issues during the planning and design stage, including the preparation of the pre-tender stage health and safety plan [7]. The regulation also recognizes other parties, including the client, designer, principal contractor and sub-contractors, as having responsibilities for health and safety management on a construction project. It highlights the importance of multi-party collaboration for safe construction. The level of awareness of the distinctive duties and how well these are coordinated during the various phases of the construction project underpins health and safety [50]. Researchers

\footnotetext{
${ }^{1}$ Referred to as health and safety (H\&S) and operational health and safety (OHS) in different parts of the world: the focus in
} 
have become involved in developing short courses for construction professionals, adopting integrated problembased and collaborative learning approach, to help them understand these CDM roles and duties [47].

An early CDM implementation study [7] suggests designers need to indicate a knowledge and understanding of how risks and hazards to health and safety can arise in construction and how they can be avoided or reduced through design. Some designers, especially those in design-build firms, are able to address construction worker safety in their designs [21]. These designers work with their colleagues who are responsible for construction of the project. By working together in the same firm, they begin to appreciate each other's concerns. Good ideas will be remembered and used on subsequent projects. Nevertheless, many designers, who are not part of designbuild firms, note that they lack the skills and training to address construction worker safety. This brings up the need for a central body of knowledge available for designers to address safety in their designs. To address this, Gambatese and colleagues [23] accumulated over four hundred design suggestions for construction safety through literature search, construction industry personnel interview, worker safety manuals, safety design manuals and checklists. These design suggestions were compiled in the 'Design for Construction Safety Toolbox'.

The relationship between construction fatalities and design has been investigated by Behm [8]. This research was rooted in the US NIOSH Fatality Assessment Control and Evaluation (FACE) program, which provides approximately 500 construction industry fatality descriptions, including a detailed incident narrative and recommendations (www.cdc.gov/niosh/face/). It used statistical hypothesis testing to examine 224 fatality investigation reports, and the results suggested that $42 \%$ of the fatalities reviewed were linked to design issues; suggesting that the associated risk that contributed to the incident would have been reduced or eliminated had construction safety been considered in design. The research established a link between construction fatalities and design for construction safety.

Gambatese et al. [22], like Behm [8], provide retrospective evidence that design had an impact on construction site safety. Fatalities that occurred during construction of thermal and moisture protection, doors and windows (including skylights), and metal design elements were more often related to design issues. This finding was largely due to: 'the prevention of falls when erecting structural steel framing and while building and maintaining roofs where permanent anchor points, lifeline systems, and other forms of permanent fall protection could be designed into the permanent features of the structure' [22: p. 678]. In a directly related finding, the analysis revealed that: 'roofing and structural steel constructors would benefit mostly from the implementation of the design for safety concept' [22: p. 678]. This finding indicates that design for safety suggestions and 
modifications may have a positive impact on fall prevention and protection measures. As identified earlier, these are a major cause of fatalities in construction.

Being a work framework rather than a specific safety knowledge body like the toolbox, the Construction Hazard Assessment Implication Review (CHAIR) method provides a systematic evaluation for the construction, maintenance, repair, and demolition safety issues associated with design [73]. It is based on hazard and operability studies (HAZOPs) [38] to develop a process for evaluating occupational health and safety (OHS) risk implications in construction design. The CHAIR consists of a three-stage review by multidisciplinary teams, involving all stakeholders in design, construction, and use of facility. The first review occurs at the conceptual design phase. At this stage, the design is divided into logical components and, for each component, sources of OHS risk are identified and assessed. Taking place prior to construction, after the detailed design is completed; the second review focuses on OHS issues arising in the construction and demolition phases of the project, while the third review focuses on maintenance and repair of the facility. Trialed by several projects, this innovative adaptation of HAZOP study method to construction demonstrates that risk assessment methods can have genuine value if they are thoughtfully implemented.

To improve construction safety, Atkinson et al. [5] identify a number of practical actions that designers can take, including asking the contractor how work will be constructed; finding out component sizes for safe installation; coordinating the program for safe sequencing of work and ensuring the contractor has in-depth understanding of the design rationale. However, the prevalence of traditional design-bid-build contracting arrangements and the resulting complex hierarchy of subcontracting on any modern building create a significant organizational distance between designers in any domain and the relevant subcontractors who will actually perform the work. Coupled with designers' aversion to dictating means and methods due to liability concerns, there is still significant reluctance on the part of designers to take an active role in addressing construction safety [23]. There are significant challenges in implementing these actions, even in new forms of procurement where designers and contractors do work more closely together, and concerns that changes in design are often only implemented as attempts to protect the designer from liability rather than to effect any real change in design to support safety [64]. There is a dearth of research and practical experience in really incorporating safety considerations in design at the early stages, where it still can have real impact.

Design for construction safety requires collaboration of the designer, owner, constructor, and other project parties for it to be meaningful [22], and such multi-party collaboration is emphasized in CDM regulations. Yet, Gambatese et al. [22] note that it is incorrect to assume that a focus on design for safety will automatically 
eliminate construction site fatalities. It is one element within a more holistic approach to minimizing construction project risk and enhancing worker safety, through multi-level risk assessment and hazard prevention mechanisms throughout the delivery of a building project. There is more work to do to establish a robust evidence base to show the aspects of construction safety where design has the largest role to play. Yet the work discussed here indicates that the quality and nature of design do have some impact on construction safety. Hence, in the next section, we begin the review of the first strand of literature by considering the use of digital tools for managing safety through the construction phase, and then continue in the following section, by considering the use of tools in the design phase.

\section{Digital tools for managing safety through construction}

Researchers have developed a range of new tools for use in the construction phase to help contractors achieve safety in their projects. Digital technologies, such as the online databases, VR, GIS, 4D CAD, BIM, sensing/warning technologies etc., are widely applied in these tools for site hazard prevention and safe project delivery. Most of these technologies are combined with each other in related investigations. This section reviews work and highlights the main characteristics of these tools.

The systems developed through such research are aimed at different levels of project, product, process and operation in construction safety management. At the project level, online databases are commonly used in assessing competence of different stakeholders, with research tools designed to enable project safety information queries and communication within companies [e.g. 74]. The product indicates the building and infrastructure design: as discussed below, one system named Design-For-Safety-Process (DFSP), applied VR and database technologies to assist users in identifying potential the construction risks contained in the design at the construction stage $[26,27]$. Substantial efforts have been made at the process level to improve safety. Almost all of them take advantage of 4D CAD to analyze on-site dynamics to enable safe project delivery. Geographical Information Systems (GIS) and BIM have also become used in conjunction with 4D CAD to better understand construction safety issues by considering environment impact and design information. At the operation level on the construction site, 4D CAD has been applied, through the Construction Hazard Assessment with Spatial and Temporal Exposure (CHASTE) tool, described below, used to analyze detailed safety information [53]; and the Computer Image Generation for Job Simulation (CIGJS) system [39], which proposes photorealistic VR and the use of virtual humans for job safety analysis. 
A distinction is made between entity-based and BIM-based CAD (object-oriented) systems [65], and 4D related construction safety studies are categorized accordingly. Entity-based CAD makes use of limited design information from drafting tools such as Autodesk AutoCAD to help clarify safety issues, while the object-based CAD contains more complete design information such as walls, columns, windows, etc. using BIM systems. The main tools are summarized in Table 1, and they are discussed in more detail in the following sub-sections. Note that only one of the tools listed in this Table deals with the product aspect as defined above, which relates to design for safety.

$<<$ Insert Table 1 here >>

\subsection{Online Databases}

Online databases have been developed to assess competence and to detect potential risks and hazards. A prototype online system has been developed by $\mathrm{Yu}$ [74] to help clients assess the competence of potential, CDM coordinators, designers, and principal contractors. The UK's CDM Regulations 2007 [29] and its Approved Code of Practice established 'Core Criteria' to guide the client in assessing these duty-holders' health and safety competence in the outset of a project. The web based tool uses Artificial Intelligence (AI) to support their decision-making through this competence assessment processes that may involve regulation checking, risk identification and control, incident information capture and analysis.

The Construction Safety and Health Monitoring (CSHM) system [15] was created as a detector of potential risks and hazards, and a warning sign to areas of construction activities that require immediate corrective action. Leveraging the Internet advantages, the web-based CSHM enables remote access, speedy data collection, retrieval, and documentation. A knowledge base was included in the design to enable online expert advice and instructions. CSHM allows the user to monitor the project performance over a certain period through analysis of the scores given to some selected parameters. Key data can be transformed into charts, curves, and tables by the database. Data is reported through Trend/Movement, Comparing between Projects; and Executive reports. The CSHM accelerates the monitoring and assessing of performance safety and health management tasks within organizations. Both of these examples are focused on managing safety at the project-level.

\subsection{Virtual Reality}

Virtual reality (VR) is a term used to describe a set of hardware and software technologies used to provide interactive, real-time, 3D computer applications $[10,71]$. These technologies have been used for training 
construction professionals in a risk-free and realistic virtual construction site, e.g. the Building Management Simulation Centre [67]. Hadikusumo et al. [26,27] adopted VR for construction safety research by creating the DFSP database. This VR-based DFSP tool helped to identify safety hazards inherited during the building construction phase that were actually produced during the design phase. It incorporated a theory of accident causation, which lists common unsafe acts and conditions, in the investigation of safety hazards. These unsafe acts and conditions were supplemented with other sources in the research from local accident reports and regulations to create the DFSP database.

The DFSP contains a 'construction component/object type' and an 'accident precaution' database. The former has all construction component/object types used in virtually real construction projects, such as beam, wall, column, slab, pre-cast slab and pre-cast stairway, while the latter encompasses all possible accident precautions that can be used to prevent the occurrence of an accident due to a possible safety hazard. For the purpose of user interaction with virtually real construction components, processes and DFSP database, four VR functions were provided in the system: collision detection, terrain following, geometry picking, and 3D tape measurement. These functions enabled a better walk-through environment, modeling of falls related to height behavior, object picking to trigger DFSP database, and tape measurement to measure dimensions of an object for the purpose of safety hazards identification since some of the safety regulations state required dimensions. This VR system featured a kind of knowledge-based function and 4D modeling, but mainly depended on human cognition when applying it.

Virtual Construction Laboratory (VCL) [37] is a knowledge-based VR system, developed to enable the planner to conduct virtual experiments of innovative construction technologies and processes. It has the ability to dynamically visualize the construction site environment, and enables the construction planner to identify any possible health and safety problems of the site layout before construction begins. Compared with other VR based real-field construction management systems, it provided more interactive capabilities to mock up different construction scenarios rather than mere visualization and dynamic navigation of construction site. The core parts of VCL consist of a database to store related resource and activity information for generating on-site construction situations, and a knowledge base to contain heuristics and relevant regulations that provide guidance and assistance on site planning and layout, site operations and arrangement. This VR system provides the potential extensibility in its system structure and database for construction safety management, and hence allows the system to examine safety issues in the construction process. 
The CIGJS system [39] supports job safety analysis by applying VR technologies to generate a virtual human. Because this analysis technique derives from manufacturing, where roles are tightly defined along an assembly line, it has limitations in a proactive risk analysis of new tasks or work conditions within construction.

Modifying the technique to construction, CIGJS seeks to provide realistic simulations of actual work situations, contributing to job safety analyses to improve their effectiveness and usability in routine work situations, including construction work at an operational level, and to make the use of job safety analysis possible also at the design stage. Its distinguished features consist of virtual images, animation, and 3D interactive environment. A parametric virtual human is applied in the system to describe human body and workers' skills in a photorealistic VR environment. The new approach of job safety analysis combining with CIGJS permits easier, faster, and much more intuitive analysis of the hazards potentially present in each sub-task, and their effective control. The workers themselves play an important role in defining the simulation parameters, thus actively contributing to the health and safety of the specific workplace they are already working in or they will operate in. It has great potentials in the field of education and training of workers on correct and safe working procedures.

\subsection{Geographic Information Systems}

Geographic Information Systems (GIS) provides an approach to considering construction safety from the macro perspective as they contain detailed information regarding the environment. In the MBA-block building project in India, Bansal [6] applied GIS to safety planning because of environmental issues such as conditions, site topography, thermal comfort, access route planning influence workers safety. These environmental factors cannot be modeled with BIM and 4D CAD because they lack geospatial data by using GIS. The work facilitated 4D modeling, geospatial analysis and topography modeling in the development of safe execution sequences. A 3D model was developed along with its surrounding topography and schedule, and these were linked together within the same environment. During the safety review process, if a planned sequence results in a hazard situation, it may be corrected within the GIS itself before actual implementation. The research also discussed the use of GIS in the development of safety databases from which safety information can be retrieved and linked with the activities of the schedule or components of a building model. The combination of 4D modeling along with topographical conditions and a safety database in a single environment assists safety planners in examining what safety measures are required when, where and why. 
GIS was also integrated into a Decision Support System (DSS) to assist construction engineers in safety monitoring and controlling excavation conditions [14]. In this work, the authors consider foundation excavation as one of the construction activities prone to hazard conditions, and apply safety oriented instrumentation programs to address design issues. The DSS also can provide safeguards by indicating behavior about threshold limits, and showing a forewarning of any adverse effects of construction. It integrated GIS's graphical displays with a 'disaster reasoning' engine that helps the project manager to monitor and control the excavation progress. Such tools show how GIS is becoming used to address construction safety in combination with a range of other digital technologies.

\subsection{Entity-based 4D CAD}

Space-time conflict analysis [4] revealed that on-site workspace congestion can result in multiple clashes including design conflicts, safety hazards, access blockages, damage, space obstructions, work interruptions, etc. Mallasi [41] applied entity-based 4D CAD technology to detecting workspace congestion to identify potential on-site safety hazards. The research approach to detecting space-time congestion utilized critical Space-Time Analysis (CSA) in 4D visualization. This associates certain visual features for workspace planning with the workspace competition between different construction activities. It deals particularly with analyzing this spacetime competition that occurs between activities. The research focus is to quantify the nature of this competition by assessing the criticality of the workspace conflicts between activities sharing the same execution space (Figure 1). A key assumption in the research is that the dynamic nature of workspace usage and change is traced continually to accommodate space connectivity in the fourth dimension. Once the space connectivity mechanism is established, it is possible to quantify the particular effect of critical spaces on the construction work progress. The Patterns Execution and Critical Analysis of Site-space Organization (PECASO) prototype was developed in this work to encapsulate and evaluate the outcome of the CSA.

$<<$ Insert Figure 1 here $>>$

Benjaoran et al. [9] demonstrated a rule-based system for safety and construction management using the entitybased 4D CAD model. The system targeted the working-at-height risk because falls were the most frequently occurring types of construction accidents resulting in fatalities or severe injuries [34,35]. Fall accidents 
accounted for the largest percentage of all recorded accidents, about 52\%, and are often associated with workers on roofs, scaffolds, ladders, and floors with openings. The study aimed to formulate a rule-based system that automates the process of identifying hazardous situations. Many factors related to details of both building components and activities (i.e. component type, dimension, placement, working space, activity type, sequence, and materials and equipment) are used as input data. These factors are systematically examined to find any working-at-height hazards. After hazards are identified, the rule-based system also suggests proper safety measures including safety activities or requirements. While being implemented, the rule-based system can be updated and maintained by the safety officers. The rule-based algorithms for working-at-height hazards are formulated, embedded and visualized in the 4D CAD model.

Advantages of the rule-based 4D safety system on a project include abilities to identify working-at-height hazards according to the progress of the construction project; to discover different building components with the hazards at their own placements; to give safety measure advice; to integrate safety measures into the construction schedule; to enable people to reveal problems in the original design and schedule; and to support control of safety measures. Nevertheless, the limitation of this research using an automated approach is that a hard-coded algorithm is closed, and cannot make complex design decisions that need human creativity or knowledge to be involved in some circumstances. Applying open-ended, knowledge-based, interactive approaches can compensate for this weakness. Expert knowledge in risk identification and hazard prevention hence can be updated, and human creativity has chances to be applied during design decision processes. To forecast safety risks in construction projects, Rozenfeld et al. [53] created an automated tool named CHASTE to analyze various on-site risks at appropriate levels of detail and reliability for different planning windows and managerial purposes. CHASTE explicitly accounts for the fact that construction workers are frequently endangered by activities performed by teams other than their own. The risks to which workers are exposed change through time, as the activities performed and the physical environment of construction sites change. Because intensive hazard analyses at construction sites are rarely performed [59], and hazard identification levels are often far from ideal [13], CHASTE is a suitable tool for predicting risk levels in support of proactive safety management at construction sites. It is a time- and space-dependent model that can quantify risk levels by means of automated calculations, which enables more efficient management of construction safety. The job safety analyses of common construction tasks in CHASTE are carried out using the Construction Job Safety Analysis (CJSA) method [54], which is an extension of job safety analysis. The CJSA knowledge base must be prepared for each national or regional construction industry because it is dependent on local working 
culture. The use of loss-of-control events is critical in CHASTE as every work stage within each activity performed on a construction site has numerous typical 'loss-of-control' events, such as 'dropping a tool', 'falling from a ladder' or 'formwork collapse'. Each such event has a distinct likelihood of occurrence dependent on team size, skill, space, climatic conditions and various other factors. The CJSA knowledge base is a substantial knowledge base of loss-of-control events and their probabilities for most of the activity types which are common in reinforced concrete construction. A limitation in the CHASTE process as presented is that no human factors, such as short eyesight, or sickness, were considered in computing the probabilities of loss-ofcontrol events.

\subsection{BIM-based 4D CAD}

The VTT Technical Research Centre of Finland reports on-going research development of BIM-based safety management and communication system [57]. BIM-based 4D CAD was utilized as a central technology for construction site safety related planning activities. It presented how 4D site layout and safety related planning activities can be carried out using the BIM software Tekla Structures. It also identified opportunities to promote safety with the help of 4D BIM by involving partners such as designers, contractors, safety specialists, occupational healthcare etc. The research aimed to develop and test solutions for the planning and management of construction site safety using dynamic 4D site models. For testing, the researchers chose the completed Mäntylinna residential building project from Skanska to examine railing safety issues in construction. Construction schedules were linked with 1) the building parts, 2) the temporary structures, and 3) site production equipment.

Some advantages in the research showed possibilities for improving construction safety using commercially available BIM tools. Tekla Structures was selected for the 4D BIM work not only because of its sophisticated 4D functions, but also its real structural model of the building project as a basis for safety planning. This model corresponds to the construction work at site including the assemblies as the building is designed to be built. As part of the modeling and visualization tests, a set of suitable visualization rules were developed for temporarily used safety equipment. The rule-set can be used and developed for different purposes in pilots. Disadvantages are that safety-related custom components for the selected modeling software had to be developed in the project, and the needed, but missing, site layout and safety planning components created in cooperation with the contractor. The research showed that BIM models created in the design process can be developed to serve site 
and safety planning by adding the planned temporary site and safety arrangements to the model created in the architectural design or structural engineering stages.

Research efforts in applying 4D-BIM further extended to the analyses of structural safety during construction processes. Hu et al. [32,33,75] demonstrated this through the system, Safety Analysis of Building in Construction (SABIC). Their work identifies building structure and safety analyses that can be carried out at several time points during the construction process, rebuilding static structural models manually at each time point, and conducting probability-based calculations. However, not only the structure but also the material behavior and loading conditions changed dynamically during the construction process. To address this ignored 'time-dependent structure' problem, the research proposed SABIC to analyze building structure safety based on the theory of Bayes Dynamic Linear Model (DLM) [44] during the construction process. Applying Industry Foundation Class (IFC) standards ${ }^{2}$, the system can convert a BIM-based architectural model into a BIM-based structural model with extra information of construction process, resistance model, and loading conditions for time-dependent structural analysis. The research highlighted a concern about structural safety during the construction process, which added another dimension in construction safety considerations. Further enhancement of the system lies in improving the accuracy and efficiency when generating a structural model from architectural model; analyzing support system and automatic alteration of construction plan according to the results, etc.

\subsection{Sensing and warning technologies}

Technological advances in information, sensing, visualization, and spatial temporal analysis technologies are enabling new forms of spatial awareness of construction job site conditions $[62,69]$. Combined with effective management practices, these technologies have the potential to decrease safety risks on job sites at an operational level. Teizer et al. [61] summarized the related technologies, approaches, and their features. The basic idea behind these technical approaches is that job site safety risks can be improved by detecting, modeling, and tracking 3D boundaries around hazardous zones, and then by classifying and separating them from the active construction workspace. Kim et al. [36] described the sparse point cloud approach to modeling static objects or zones that might cause danger or have proven to have hazardous potential. Applying this approach,

\footnotetext{
${ }^{2}$ These are now called "BuildingSMART standards"
} 
McLaughlin et al. [42] created an automated obstacle avoidance support system to allow machines to navigate and operate safely.

In order to detect moving resources like machines, workers or materials within the workspace, location sensing techniques like Radio Frequency Identification (RFID) [56], Ultra-Wideband (UWB) nodes [20], and Global Positioning System (GPS) [46] are applicable. Video rate range imaging is a technique to rapidly detect, model, and track the position of static and moving obstacles from a static or moving sensor platform [62]. In obstacle avoidance systems, it uses video laser range scanning technology to rapidly detect, model, and track the position of static and moving obstacles. An experimental study demonstrated that position, dimension, direction, and speed measurements had an accuracy level compatible with the requirements of active safety features for construction. The combination of this approach with other sensing and information technologies such as 4D CAD, GPS, RFID, GIS, etc. promises to improve construction engineering and management in methods, material tracking, visualization, and automation.

These technologies can be also used to create active warning systems to protect workers from risk situations in dynamic construction sites. Commonly available Personal Protective Equipment (PPE), such as hard hats, safety shoes, goggles, etc., only provides passive protection, whereas active warning systems can generate warnings or feedback to the worker when risks come into range. Teizer et al.'s [60] study of application of real-time proximity and alert technology for daily construction operations using Radio Frequency proved the effectiveness of the proposed approach to enhancing safety in the construction environment.

These applications, however, still suffer numerous shortcomings. Teizer et al. [61] highlighted the fact that any wireless devices for obstacle avoidance system applications require tagging of each individual resource on a job site (human, material, and equipment). This approach is less reliable for safety applications in case of unforeseen events involving mistakenly untagged resources. Other potential problems also include limited signal strength through obstructions resulting in lower performance, the unavailability of GPS satellites or contact to a base station to determine precise locations, the high cost of tags, etc.

\subsection{Implications of current digital applications for construction safety}

This literature has developed a strong set of applications for digital technologies to support construction safety at project, product, process, and operation level. These technologies, as shown in Table 1, and discussed in the previous sub-sections, include online databases, VR, GIS, 4D CAD, BIM and sensing/warning technologies. 
Such technologies are often used in combination with each other, as illustrated, for example in the PECASO tool in Figure 2. Some of the tools reviewed are specifically designed to manage site safety risks, with section 3.6 in particular dealing with sensing and warning technologies that can be used directly on site in real-time. Another category is those designed to visualize the construction process to highlight safety implications, where technologies discussed in sections 3.1 to 3.5 deal with production planning. The different technologies reviewed are complementary. For example, GIS, on the one hand, provides an overview of construction projects and their associations with their surrounding environment, and is helpful where they encounter hazards from external conditions; BIM, on the other hand, can be used to obtain reusable information from the design phase to clarify construction safety concerns. The combined use of GIS with BIM enables a broader consideration of construction safety.

The research is not without limitations. The discussion of 4D CAD tools, in Sections 3.4 and 3.5 indicates a technological approach to planning for safety in advance of operations. A significant shortcoming of this approach is the dependence on computerized construction schedules. Construction operations are dynamic and subject to frequent changes that do not comply with originally scheduled work. Hence, digital schedules are rarely updated sufficiently frequently to accurately reflect all operations underway at any given point in time; though tools that are based on an operational production control model rather than a 4D based process model may reflect this more accurately. An alternative approach is to obtain the most reliable plan possible in the multidisciplinary construction field using collaborative 4D construction planning [76].

Within this research trajectory, there are significant ways that this research could be extended. For example, research that combines the VR-based CIGJS method with CHASTE could begin to take human factors into account in loss-of-control events. VR technology in the meantime can play a key role in educating and training construction workers. Additionally, existing research on sensing and warning technologies shows their powerful effects on real-time site monitoring to locate various resources; and the potential for further applications. Hence, both individually and in combination there is the potential for significant future research to develop this set of technologies to address construction risks and hazards prevention.

\section{Digital tools for managing construction safety through design}

Digital approaches to construction safety in the design phase are less mature than those in the construction phase. Compared with the range of digital applications for safety in the construction phase, few tools are available in 
the design phase to help designers achieve construction safety. Apart from the DFSP tool that deals with design issues at the construction phase, there is significant work on a knowledge based design decision toolkit, and on using BIM to enable construction safety by design through rule-checking approaches. An overview of the tools found in this review is given in Table 2.

$<<$ Insert Table 2 here $>>$

ToolSHeD [16] is a web-based design decision tool to provide decision support for construction professionals, and help assess the risk of falling from a roof during building maintenance work. The underlying principle of ToolSHeD adopted a knowledge based approach to assess the maintenance risks of complex building situations. Knowledge acquisition was from data sources including Australian Occupational Health and Safety guidance material, industry standards and codes. An expert panel evaluated acquired knowledge to validate its effectiveness. On the basis of this work, acquired knowledge was modeled in a series of logic diagrams called 'argument trees', which represent a template for reasoning in complex situations. These diagrams provide a practical way of representing knowledge when the outcome being considered is subjective and interrelated to other issues that need to be considered simultaneously. Through its web based user interface, the ToolSHeD provides a step-by-step approach to the assessment of the risk of falling from heights presented by features of a building's design. The risk assessment prompts designers to enter information about relevant design features that experts agree could impact upon the risk of falling from height. The data entered are then used to infer a risk rating based upon a reasoning model agreed by the panel of experts. A risk report is generated as a system output to advise the designer about level of risk of falling from height (extreme, high, medium or low), and an explanation of the design factors contributing to this inferred level of risk.

The UK's Health and Safety Executive report [30] shows falls on building sites and during maintenance are the largest cause of accidents at work in the UK. To address this problem, NNC Ltd worked with AEC3 UK Ltd and BuildingSMART UK to demonstrate a knowledge-based prototype system in which proposed buildings can be tested against health and safety requirements that are graded according to levels of risk. In a pilot project in Singapore, the prototype system focused on 'roof lights' because the risk of a fall from the roof of a building is frequently associated with their installation and maintenance. A set of rules was defined for the automated assessment of safety involving knowledge of the roof, roof light, and handrail objects, the building, the site as a 
whole and the relationships that exist between these objects. The project used software technology developed for the automated building code checking. BIM systems are used to export data in the IFC format to a database. Data was then tested against rules that have been defined following consultation with health and safety experts, including regional health and safety rules. Reporting the results of completed checks was achieved through graphic and rule-browsing software provided by NovaSprint Pte Ltd that allows controlled viewing of the building by object and by rule.

These safety design tools consider safety in design to improve practices in construction or maintenance. They have different advantages and disadvantages, as shown in Table 2. The ToolSHeD system adopts regional H\&S regulations to guide risk analysis. It utilizes the web platform and hence is suitable for multi-party collaboration across the Internet. However, geometric design information of a building is not incorporated into the system. This makes it only useful for risk analysis in the maintenance phase rather than construction phase. The NNC's knowledge-based prototype takes advantage of design information from BIM for rule-based checking. Its automated rule-checking approach is based on the incorporation of regional H\&S regulations. Yet, it only targets the maintenance phase for risk analysis but not for hazard prevention in the construction phase. Its Internet-based functions are applied for online H\&S rules browsing instead of multi-party collaboration.

Given the value of considering construction safety through design as discussed in Section 2, the review of this strand of literature, in this and the preceding section, reveals a relative lack of digital tools to support it. Digital tools have been developed for managing construction safety within the construction phase, but few are available to support design for construction safety. Hence the review of this strand of the literature suggests particular opportunities for research to develop tools to support construction safety through digital design, especially in the context of the wider emphasis on design in policy making in the UK and elsewhere.

\section{Construction safety and digital practices in design}

The second strand of research, which is more briefly considered in this paper, is a literature that empirically studies practice, within which authors have examined safety critical operations, the practices of using technologies, and design practices. This literature draws on wider theories of organization and hence starts from essentially different assumptions and research traditions to the first strand. Here, safe working practices are seen as an emergent feature [43], negotiated in the context of fragmented and antagonistic safety cultures [25] and influenced by the patterns of authority and learning on construction sites [52]. Conflicts: 'between forms of 
authority and knowledge can inhibit the dissemination of good safety practice: initiatives will meet significant resistance if they contradict the experiential knowledge of site operatives; if they do not make use of this experiential knowledge, they may fail to address hazards fully; methods of site learning, particularly in the development of innovative practice, are inherently hazardous. '[52: p.568-9]

Thus the focus is on the divergent forms of knowledge within complex organizations, rather than individual error. Systemic accidents are described by Perrrow $[48,49]$ as normal (but rare) within complex organizations because they have non-linear and multiple interdependencies between their sub-systems. He sees complex organizations dealing with incompatible needs for centralization, to cope with the tight coupling and interaction between sub-systems, and for decentralized decision-making to manage and contain problems in ongoing operations. Hence work in any system deals with danger and failure as well as safety [25]. Accidents are described as 'normal' as, paradoxically, tight-coupling within complex organization is needed to manage interaction risks; and loose-coupling is needed to manage risks that arise in ongoing operations [48]. In ongoing operations within such contexts, heedful inter-relating or 'mindful' action is essential, to challenge assumptions, check and validate proposed solutions; making sense of and respond to unexpected situations that arise.

The introduction of digital technologies is seen as having both intended and unintended effects. For example, technologies are often introduced to increase managerial oversight and control [63]. Yet as they take control away from workers, digital technologies can hinder their 'mindful' action, increasing the potential for mistakes and accidents [68]. Often digital systems do not encourage the active challenging of assumptions, checking and validating of solutions across sources and ongoing sensemaking. Weick argues that: 'It is the very self-contained character of the electronic cosmos that tempts people, when data make less and less sense, to retain assumptions rather than move to different orders of reasoning.' [68: p. 56]. Hence, digital technologies may lead to errors by increasing 'mindlessness' as: 'Reliance on a single, uncontradicted data source can give people a feeling of omniscience, but because these data are flawed in unrecognized ways they lead to nonadaptive action' [68: p. 57].

While much of this existing research has focused on operations, in safety critical contexts such as nuclear power; and space exploration, the insights it provides are also relevant to design, where Henderson describes a visual culture of engineering coming into conflict with 'inflexible databases' [28]. It has a particular relevance to the challenge of considering construction safety in design; where forms of knowing through written reports and documentation are dominant in the professions; and forms of knowing through experiential learning are dominant in the trades [24,52]. Within the construction industry, some activities across design and construction 
are becoming more tightly coupled through the use of BIM technologies [19,55,70]; while the use of digital technologies is also changing communication patterns in other parts of project organization by presenting data in formats that are not accessible to all members of the team. In the discussion of risk in the conceptual stage of projects, it has been argued that: 'the use of information technology and integration of various information systems appear to have a more positive influence on the use of risk management in the conceptual phase of a project life cycle than the type of organization structure.' [66: p.168], but more research is needed to examine the relationships between digital design and construction safety and to examine where and how these lead to mindful or unmindful practices.

In summary, at the same time as research in the first strand has developed novel ways to use digital technologies in addressing safety issues in construction, this second strand of research raises a concern about 'mindlessness' in the broader use of digital technologies, which can have unintended and negative impacts on safety. This literature suggests a need for further research to investigate relationships between construction safety and digital design. It has implications for research in the first strand that looks to develop new tools that specifically address safety. For example, it suggests that systems must encourage users to check and make sense of unexpected data rather than rely on managerial oversight.

\section{Discussion and conclusions}

It was the chief engineer on a construction site who introduced the metaphor of the watch-maker, used in the opening sentence of this paper, to explain his frustration at the general reluctance of designers to think about material properties, such as the expansion and contraction of large structures, instead believing that you can 'just build a model and off you go.' He described the result as 'watch-maker tolerances.' Yet, he then immediately went on to speculate about potential positive outcomes of using digital technologies, noting that the digital world could help you to play with tolerances, but that his concern is that it focuses attention on accuracy, rather than an understanding of how to catch problems when they arise. As set out in the introduction, it is this engagement with practitioners seeking to both sustain and develop safe construction practices and the questions about what kind of digital technologies support safe working practices that motivate the discussion in this paper. This paper's contribution is to review and juxtapose two different strands of research that are relevant to understanding relationships between construction safety and digital design. These literatures suggest very 
different approaches to the questions raised at the beginning of the paper. Taken separately, the first strand of literature shows there is a substantial body of research on applications of digital technologies to site safety issues, although very few tools for construction safety through design. The second strand of literature, based on empirical studies of safety critical, digital and design practices, raises a concern about 'mindlessness' in the use of technologies. Yet what is exciting is that the juxtaposition of these two strands shows how the second strand has implications for research in the first.

This is particularly pertinent given the changing nature of practices. While much professional work has become digitally-mediated and distributed; the making of buildings and infrastructure involves substantial and local physical labor. Yet this work is not unchanged by the digital economy. The new digitally-enabled processes change the distribution and nature of design practices and supply-chains, altering the materials and information that are available at site. With building modeling, for example, greater detail is developed earlier in a project. In any particular project, safe practices both draw on standardized regulations and tools and are locally emergent.

Bringing the strands of our review together suggests new kinds of interventions, such as the development of tools and processes for multi-party collaboration on safety around digital models. These do not attempt to provide a 'complete solution' to safety issues. Rather such new tools and practices informed by this review will instead be judged by the extent to which they foster consideration of safety through the kind of 'mindful' actions that challenge assumptions, check and validate proposed solutions; making sense of and responding to unexpected situations that arise. New directions of research on construction safety and digital design could, for example, focus on technologies that enable constructors to share their knowledge with designers; using the visualization potential of new technologies to bring knowledge of the construction site into design.

\section{References}

[1] Eurostat, the statistical office of the European Communities http://epp.eurostat.ec.europa.eu/.

[2] LABORSTA, an International Labour Office database on labour statistics operated by the ILO Department of Statistics http://laborsta.ilo.org/.

[3] M.D.M. Aires, M.C.R. Gámez, A. Gibb, Prevention through design: The effect of European Directives on construction workplace accidents, Safety Science 48 (2) (2010) 248-258.

[4] B. Akinci, M. Fischer, R. Levitt, R. Carlson, Formalization and automation of time-space conflict analysis, Journal of Computing in Civil Engineering 16 (2) (2002) 124-134.

[5] A.R. Atkinson, R. Westall, The relationship between integrated design and construction and safety on construction projects, Construction Management \& Economics 28 (9) (2010) 1007-1017.

[6] V.K. Bansal, Application of geographic information systems in construction safety planning, International Journal of Project Management 29 (1) (2011) 66-77.

[7] T. Baxendale, Jones, O., Construction design and management safety regulations in practice-progress on implementation, International Journal of Project Management 18 (1) (2000) 33-40. 
[8] M. Behm, Linking construction fatalities to the design for construction safety concept, Safety Science 43 (8) (2005) 589-611.

[9] V. Benjaoran, S. Bhokha, An integrated safety management with construction management using 4D CAD model, Safety Science 48 (3) (2010) 395-403.

[10] D. Bouchlaghem, H. Shang, J. Whyte, A. Ganah, Visualisation in architecture, engineering and construction (AEC), Automation in Construction 14 (3) (2005) 287-295.

[11] C. Brace, A. Gibb, M. Pendlebury, P. Bust, Health and safety in the construction industry: Underlying causes of construction fatal accidents - External research, Secretary of State for Work and Pensions, Inquiry into the underlying causes of construction fatal accidents, Loughborough University, Loughborough 2009 http://www.hse.gov.uk/construction/resources/phase2ext.pdf.

[12] E. Brynjolfsson, B. Kahin, Understanding the Digital Economy: Data, Tools and Research, MIT Press, Cambridge, MA, 2000.

[13] G. Carter, S.D. Smith, Safety hazard identification on construction projects, Journal of Construction Engineering and Management 132 (2) (2006) 197-205.

[14] M.Y. Cheng, C.H. Ko, C. C.H., Computer-aided DSS for safety monitoring of geotechnical construction, Automation in Construction 11 (4) (2002) 375- 390

[15] S. Cheung, Cheung, K.K.W., Suen, H.C.H., CSHM: Web-based safety and health monitoring system for construction management, Journal of Safety Research 35 (2) (2004) 159-170.

[16] T. Cooke, Lingard, H., Blismas, N., Stranieri, A., ToolSHeD: The development and evaluation of a decision support tool for health and safety in construction design, Engineering, Engineering, Construction and Architectural Management 15 (4) (2008) 336-351.

[17] J. Davison, The development of a knowledge based system to deliver health and safety information to designers in the construction industry, London, 2003.

[18] R. Donaghy, One Death Is Too Many: Inquiry into the Underlying Causes of Construction Fatal Accidents, Report to the Secretary of State for Work and Pensions, The Stationery Office, Norwich, 2009.

[19] C. Eastman, P. Teicholz, R. Sacks, K. Liston, BIM Handbook: A guide to building information modeling for owners, managers, designers, engineers and contractors, Wiley, 2008.

[20] R.J. Fontana, Recent system applications of short-pulse ultra-wideband (UWB) technology, IEEE Transactions on Microwave Theory and Techniques 52 (9) (2004) 2087-2104

[21] J. Gambatese, J. Hinze, Addressing construction worker safety in the design phase Designing for construction worker safety, Automation in Construction 8 (6) (1999) 643-649.

[22] J.A. Gambatese, M. Behm, S. Rajendran, Design's role in construction accident causality and prevention: Perspectives from an expert panel, Safety Science 46 (4) (2008) 675-691.

[23] J.A. Gambatese, J.W. Hinze, C.T. Haas, Tool to Design for Construction Worker Safety, Journal of Architectural Engineering 3 (1) (1997) 32-41.

[24] S. Gherardi, D. Nicolini, To Transfer is to Transform: The Circulation of Safety Knowledge, Organization 7 (2) (2000) 329-348.

[25] S. Gherardi, D. Nicolini, F. Odella, What Do You Mean By Safety? Conflicting Perspectives on Accident Causation and Safety Management in a Construction Firm, Journal of Contingencies \& Crisis Management 6 (4) (1998) 202-213.

[26] B.H.W. Hadikusumo, S. Rowlinson, Capturing Safety Knowledge Using Design-for-Safety-Process Tool, Journal of Construction Engineering and Management 130 (2) (2004) 281-289.

[27] B.H.W. Hadikusumo, S. Rowlinson, Integration of virtually real construction model and design-forsafety-process database Automation in Construction 11 ( 5 ) (2002) 501-509.

[28] K. Henderson, On Line and On Paper: Visual representations, visual culture and computer graphics in design engineering, MIT Press, Cambridge, MA, 1999.

[29] HMSO, Construction (Design and Management) Regulations Her Majesty's Stationary Office, 2007.

[30] HSE, Blackspot Construction: a study of five years fatal accidents in the building and civil engineering industries, Health and Safety Executive, 1988.

[31] HSE, Phase 1 Report: Underlying causes of construction fatal accidents - A comprehensive review of recent work to consolidate and summarise existing knowledge, Health and Safety Executive,

Construction Division, London, 2009.

[32] Z.Z. Hu, J.P. Zhang, BIM- and 4D-based integrated solution of analysis and management for conflicts and structural safety problems during construction: 2 . Development and site trials, Automation in Construction 20 (2) (2011) 167-180.

[33] Z.Z. Hu, J.P. Zhang, Z. Deng, Construction Process Simulation and Safety Analysis Based on Building Information Model and 4D Technology, Tsinghua Science and Technology (13) (2008) 266-272.

[34] X. Huang, Hinze, J. , Analysis of construction worker fall accidents, Journal of Construction Engineering and Management 129 (3) (2003) 262-271. 
[35] C. Janicak, Fall-related deaths in the construction industry, Journal of Safety Research 29 (1) (1998) 35-42.

[36] C. Kim, C.T. Haas, K.A. Liapi, J. McLaughlin, J. Teizer, F. Bosche, Rapid Human-Assisted, Obstacle Avoidance System using Sparse Range Point Clouds, Proc., 9th Aerospace Division Int. Conf., ASCE Conf. Proc., 2004, pp. 115-122.

[37] H. Li, Ma, Z., Shen, Q., Kong, S. , Virtual experiment of innovative construction operations, Automation in Construction 12 (5) (2003) 561- 575.

[38] H. Lingard, S. Rowlinson, Occupational Health and Safety in Construction Project Management, Routledge, UK, 2005.

[39] D.B. M. Patrucco, C. Cigna, F. Fissore Computer image generation for job simulation: An effective approach to occupational Risk Analysis, Safety Science 48 (2010) 508-516.

[40] E.J. Malecki, B. Moriset, The digital economy: business organization, production processes, and regional developments, Routledge, Abingdon, 2008.

[41] Z. Mallasi, Dynamic quantification and analysis of the construction workspace congestion utilising 4D visualisation, Automation in Construction 15 (2006) 640 - 655.

[42] J. McLaughlin, S.V. Sreenivasan, C.T. Haas, K.A. Liapi, Rapid human-assisted creation of bounding models for obstacle avoidance in construction, J. Comp.-Aided Civil and Infrastructure Engineering 19 (2004) 3-15.

[43] P. Mitropoulos, G. Cupido, Safety as an Emergent Property: Investigation into the Work Practices of High-Reliability Framing Crews, Journal of Construction Engineering and Management 135 (5) (2009) 407-415.

[44] Y. Mori, B.R. Ellingwood, Reliability-based service-life assessment of aging concrete structures, Structural Engineering 119 (5) (1993) 1600-1621.

[45] National Statistics, Health and safety \I Statistics 2008/09, Health and Safety Executive (HSE) and National Statistics, London, 2010.

[46] R. Navon, Automated project performance control of construction projects, Automation in Construction 14 (4) (2005) 467-476.

[47] D. Oloke, H. Yu, H. D., Developing Practitioner Skills in Construction Health and Safety Management: An Integrated Teaching and Learning Approach, Journal for Education in the Built Environment 2 (1) (2007) 3-30.

[48] C. Perrow, The limits of safety: the enhancement of a theory of accidents, Journal of Contingencies and Crisis Management 2 (4) (1994) 212-220.

[49] C. Perrow, Normal Accidents: Living with High-Risk Technologies, Princeton University Press, Princeton, New Jersey, 1999 [1984].

[50] P. Perry, Construction safety (questions and answers: A practical approach), Thomas Telford Publishing, London, 2003.

[51] J. Reason, Human error: models and management, British Medical Journal 320 (7237 ) (2000).

[52] J. Rooke, L. Clark, Learning, knowledge and authority on site: a case of safety practice, Building Research and Information 33 (6) (2005) 561-570.

[53] O. Rozenfeld, R. Sacks, Y. Rosenfeld, 'CHASTE': construction hazard assessment with spatial and temporal exposure, Construction Management and Economics 27 (7) (2009) 625-638.

[54] O. Rozenfeld, R. Sacks, Y. Rosenfeld, H. Baum, Construction job safety analysis, Safety Science 48 (4) (2010) 491-498

[55] R. Sacks, L. Koskela, B. Dave, R.L. Owen, The Interaction of Lean and Building Information Modeling in Construction, Journal of Construction Engineering and Management 136 (9) (2010) 968 980.

[56] J. Song, C.T. Haas, C. Caldas, E. Ergen, B. Akinci, Automating the task of tracking the delivery and receipt of fabricated pipe spools in industrial projects, Automation in Construction 15 (2) (2006) 166177.

[57] K. Sulankivi, K. Kähkönen, T. Mäkelä, M. Kiviniemi, 4D-BIM for Construction Safety Planning, in: P. Barrett, Amaratunga, Dilanthi, Haigh, Richard, Keraminiyage, Kaushal \& Pathirage, Chamind (Ed.), CIB World Congress, Manchester, 2010.

[58] R. Szymberski, Construction Project Safety Planning, TAPPI Journal 80 (11) (1997) 69-74.

[59] S.L. Tang, Lee, H.K. and Wong, K. , Safety cost optimization of building projects in Hong Kong, Construction Management and Economics 15 (2) (1997) 177-186.

[60] J. Teizer, B.S. Allread, C.E. Fullerton, J. Hinze, Autonomous pro-active real-time construction worker and equipment operator proximity safety alert system, Automation in Construction 19 (5) (2010) 630640. 
[61] J. Teizer, C. H, Caldas, C.T. Haas, Real-Time Three-Dimensional Occupancy Grid Modeling for the Detection and Tracking of Construction Resources, Journal of Construction Engineering and Management 133 (11) (2007) 880-888

[62] J. Teizer, C. Kim, C.T. Haas, K.A. Liapi, C.H. Caldas, A framework for real-time 3D modeling of infrastructure, Transportation Research Record 1913 (2005) 177-186.

[63] R.J. Thomas, What Machine's Can't Do: Politics and Technology in the Industrial Enterprise, University of California Press, Berkeley and Los Angeles, CA, 1994.

[64] M. Toole, J. Gambatese, The Trajectories of Prevention through Design in Construction, Journal of Safety Research 39 (2) (2008) 225-230.

[65] T. Tse, K., Wong, K., A. and Wong, K., F. , The utilisation of building information models in nD modelling: A study of data interfacing and adoption barriers, ITcon 10 (Special Issue From 3D to nD modelling) (2005) 85-110.

[66] T.E. Uher, A.R. Toakley, Risk management in the conceptual phase of a project International Journal of Project Management 17 (3) (1999) 161-169

[67] B.D. Vries, S. Verhagen, A.J. Jessurun, Building Management Simulation Centre, Automation in Construction 13 (5) (2004) 679-687.

[68] K.E. Weick, Cosmos versus chaos: sense and nonsense in electronic contexts, Organizational Dynamics 14 (2) (1985) 51-64.

[69] J. Weingarten, G. Gruener, R. Siegwart, A state-of-the-art 3D sensor for robot navigation, Proceedings of 2004 IEE/RSJ International Conference on Intelligent Robots and Systems, Vol. September 28 October 2, Sendai, Japan, 2004.

[70] J. Whyte, Managing Digital Coordination of Design: Emerging Hybrid Practices in an Institutionalized Project Setting, Engineering Project Organization 1 (3) (2011) 159-168.

[71] J.K. Whyte, Virtual Reality and the Built Environment, Architectural Press, Oxford, 2002.

[72] S. Woo, S. Jeong, E. Mok, L. Xia, C. Choi, M. Pyeon, J. Heo, Application of WiFi-based indoor positioning system for labor tracking at construction sites: A case study in Guangzhou MTR, Automation in Construction 20 (2011) 3-13.

[73] Workcover, Chair Safety in Design Tool, WORKCOVER New South Wales, 2001.

[74] H. Yu, A knowledge based system for construction health and safety competence assessment, University of Wolverhampton, 2009.

[75] J.P. Zhang, Z.Z. Hu, BIM- and 4D-based integrated solution of analysis and management for conflicts and structural safety problems during construction: 1. Principles and methodologies, Automation in Construction 20 (2) (2011) 155-166.

[76] W. Zhou, D. Heesom, P. Georgakis, C. Nwagboso, A. Feng, An interactive approach to collaborative 4D construction planning, ITcon 14 (Special Issue: Technology Strategies for Collaborative Working) (2009) 48-58. 


\begin{tabular}{|c|c|c|c|c|}
\hline Tool/Project & Approach & Level & Technology & Citation \\
\hline $\begin{array}{l}\text { H\&S competence } \\
\text { assessment }\end{array}$ & $\begin{array}{l}\text { Assessment of duty- } \\
\text { holders competence }\end{array}$ & Project & Online databases & [74] \\
\hline $\begin{array}{l}\text { Construction Safety } \\
\text { and Health } \\
\text { Monitoring System } \\
(\mathrm{CSHM})\end{array}$ & $\begin{array}{l}\text { Monitor project } \\
\text { performance }\end{array}$ & Project & Online databases & [15] \\
\hline $\begin{array}{l}\text { Design for Safety } \\
\text { Process (DFSP) }\end{array}$ & $\begin{array}{l}\text { Simulation and review of } \\
\text { construction process for } \\
\text { design related safety issues }\end{array}$ & $\begin{array}{l}\text { Process } \\
\text { and } \\
\text { Product }\end{array}$ & VR & {$[26,27]$} \\
\hline $\begin{array}{l}\text { Virtual Construction } \\
\text { Laboratory (VCL) }\end{array}$ & $\begin{array}{l}\text { Simulation and review of } \\
\text { innovative processes }\end{array}$ & Process & VR & [37] \\
\hline MBA-black building & $\begin{array}{l}\text { Safety planning } \\
\text { considering environmental } \\
\text { conditions }\end{array}$ & Process & $\begin{array}{l}\text { GIS, entity-based 4D } \\
\text { CAD }\end{array}$ & {$[6]$} \\
\hline $\begin{array}{l}\text { Decision Support } \\
\text { System (DSS) }\end{array}$ & $\begin{array}{l}\text { Assist monitoring and } \\
\text { control of operations }\end{array}$ & Process & GIS & [14] \\
\hline $\begin{array}{l}\text { Patterns Execution } \\
\text { and Critical Analysis } \\
\text { of Site Space } \\
\text { Organization } \\
\text { (PECASO) }\end{array}$ & $\begin{array}{l}\text { Critical space-time } \\
\text { analysis }\end{array}$ & Process & Entity-based 4D CAD & [41] \\
\hline $\begin{array}{l}\text { Rule-based 4D } \\
\text { system }\end{array}$ & Rule-based & Process & Entity-based 4D CAD & [9] \\
\hline Mäntylinna building & Visualization & Process & BIM-based 4D CAD & [57] \\
\hline $\begin{array}{l}\text { Safety Analysis of } \\
\text { Building in } \\
\text { Construction } \\
\text { (SABIC) }\end{array}$ & Structural analysis & Process & BIM-based 4D CAD & [33] \\
\hline $\begin{array}{l}\text { Construction Hazard } \\
\text { Assessment with } \\
\text { Spatial and Temporal } \\
\text { Exposure (CHASTE) }\end{array}$ & $\begin{array}{l}\text { Construction job safety } \\
\text { analysis and evaluation of } \\
\text { operational risk levels }\end{array}$ & Operation & Entity-based 4D CAD & [53] \\
\hline $\begin{array}{l}\text { Computer image } \\
\text { generation for job } \\
\text { simulation (CIGJS) }\end{array}$ & $\begin{array}{l}\text { Simulation for job safety } \\
\text { analysis }\end{array}$ & Operation & VR & [39] \\
\hline $\begin{array}{l}\text { Automated obstacle } \\
\text { avoidance support } \\
\text { system }\end{array}$ & Sparse point cloud & Operation & $\begin{array}{l}\text { Laser range scanning } \\
\text { technology }\end{array}$ & [42] \\
\hline $\begin{array}{l}\text { Real-time proximity } \\
\text { and alert system }\end{array}$ & $\begin{array}{l}\text { Generate active warning or } \\
\text { feedback in real time }\end{array}$ & Operation & $\begin{array}{l}\text { Wireless \& RFID } \\
\text { communication }\end{array}$ & [60] \\
\hline $\begin{array}{l}\text { WiFi-based indoor } \\
\text { positioning system }\end{array}$ & Indoor positioning & Operation & $\begin{array}{l}\text { Wireless \& RFID } \\
\text { communication }\end{array}$ & [72] \\
\hline $\begin{array}{l}\text { Video rate range } \\
\text { imaging system }\end{array}$ & $\begin{array}{l}\text { Detect, model, and track } \\
\text { the position of static and } \\
\text { moving obstacles }\end{array}$ & Operation & $\begin{array}{l}\text { Video laser range } \\
\text { scanning technology }\end{array}$ & [62] \\
\hline
\end{tabular}

Table 1. Construction safety systems/projects applying digital technologies. 


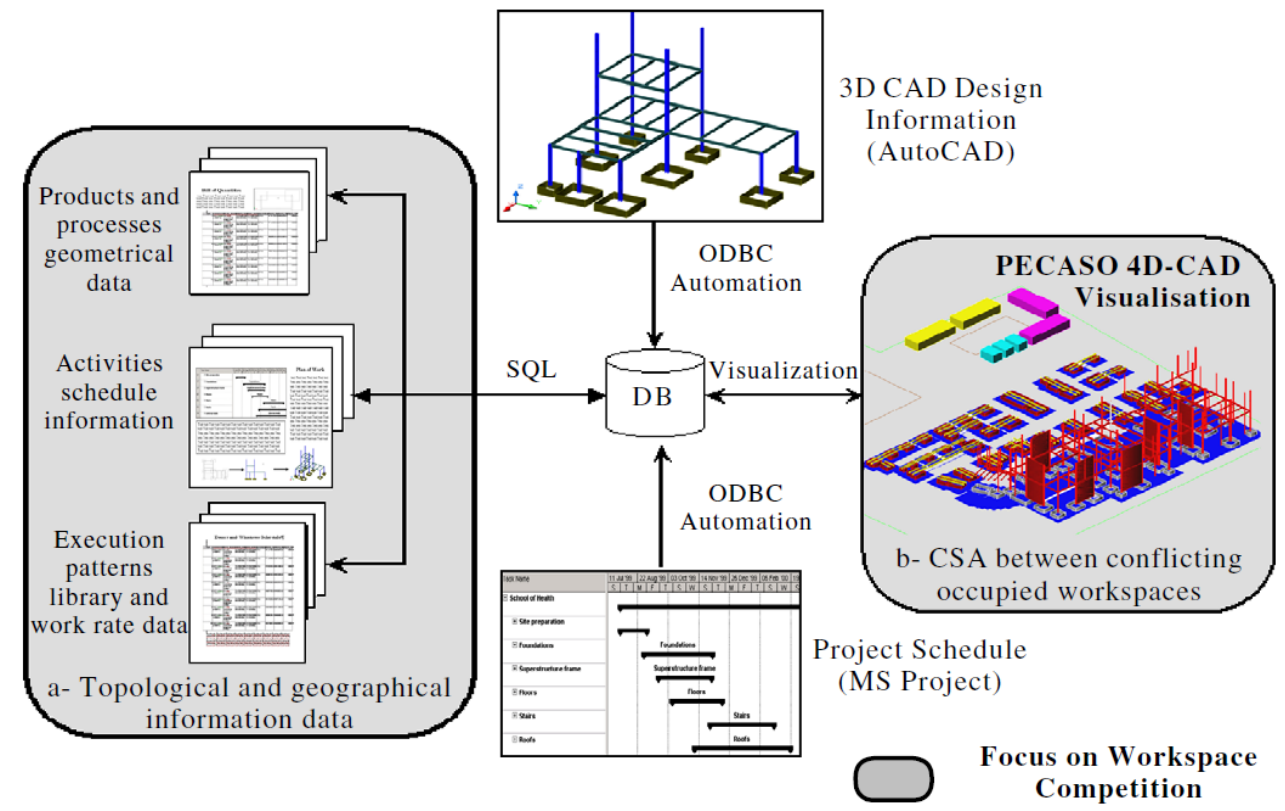

Figure 1. Framework of the PECASO tool, which utilizes 4D CAD visualization of CSA and workspace competition visualization [41]. 


\begin{tabular}{|l|l|l|l|l|l|}
\hline Tool & Approach & Technology & Usefulness & Advantage & Disadvantage \\
\hline ToolSHeD [16] & $\begin{array}{l}\text { Knowledge } \\
\text { Base }\end{array}$ & Web & $\begin{array}{l}\text { Risk } \\
\text { assessment }\end{array}$ & $\begin{array}{l}\text { Web-based } \\
\text { system suitable } \\
\text { for multi-party } \\
\text { collaboration; } \\
\text { combine with } \\
\text { regional H\&S } \\
\text { regulations }\end{array}$ & $\begin{array}{l}\text { Not integrated } \\
\text { with design } \\
\text { information; } \\
\text { applicable only } \\
\text { for maintenance } \\
\text { phase }\end{array}$ \\
\hline $\begin{array}{l}\text { The knowledge- } \\
\text { based safety } \\
\text { design analysis } \\
\text { prototype [17] }\end{array}$ & $\begin{array}{l}\text { Rule- } \\
\text { checking }\end{array}$ & BIM & $\begin{array}{l}\text { Risk } \\
\text { assessment }\end{array}$ & $\begin{array}{l}\text { Integrated with } \\
\text { design } \\
\text { information; } \\
\text { combine with } \\
\text { regional H\&S } \\
\text { regulations }\end{array}$ & $\begin{array}{l}\text { Limited Internet } \\
\text { functions for } \\
\text { H\&S rule } \\
\text { browsing; not for } \\
\text { collaboration; } \\
\text { applicable only } \\
\text { for maintenance } \\
\text { phase }\end{array}$ \\
\hline
\end{tabular}

Table 2. Digital tools for construction safety design 